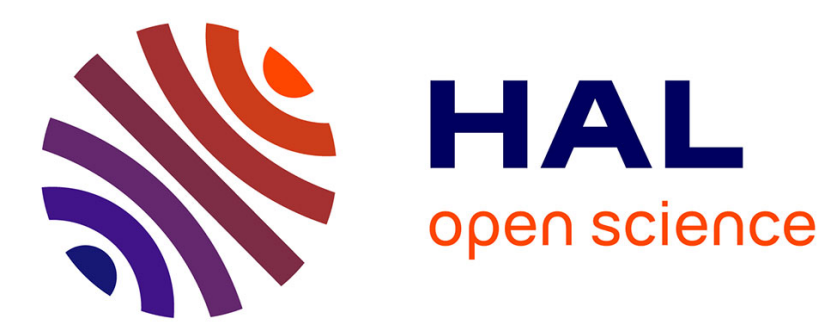

\title{
Thermo-Mechanical Modeling of Abradable Coating Wear in Aircraft Engines
}

\author{
Florence Nyssen, Alain Batailly
}

\section{To cite this version:}

Florence Nyssen, Alain Batailly. Thermo-Mechanical Modeling of Abradable Coating Wear in Aircraft Engines. Journal of Engineering for Gas Turbines and Power, 2018, 141 (2), pp.021031. 10.1115/1.4041647 . hal-01942616v2

\section{HAL Id: hal-01942616 https://hal.science/hal-01942616v2}

Submitted on 20 Mar 2019

HAL is a multi-disciplinary open access archive for the deposit and dissemination of scientific research documents, whether they are published or not. The documents may come from teaching and research institutions in France or abroad, or from public or private research centers.
L'archive ouverte pluridisciplinaire HAL, est destinée au dépôt et à la diffusion de documents scientifiques de niveau recherche, publiés ou non, émanant des établissements d'enseignement et de recherche français ou étrangers, des laboratoires publics ou privés. 


\title{
Thermo-Mechanical Modeling of Abradable Coating Wear in Aircraft Engines
}

\author{
F. Nyssen ${ }^{1}$, A. Batailly ${ }^{1}$
}

\begin{abstract}
In modern turbomachine designs, the nominal clearances between rotating bladed-disks and their surrounding casing are reduced to improve aerodynamic performances of the engine. This clearance reduction increases the risk of contacts between components and may lead to hazardous interaction phenomena. A common technical solution to mitigate such interactions consists in the deposition of an abradable coating along the casing inner surface. This enhances the engine efficiency while ensuring operational safety. However, contact interactions between blade-tips and an abradable layer may yield unexpected wear removal phenomena. The aim of this work is to investigate the numerical modeling of thermal effects within the abradable layer during contact interactions and compare it with experimental data. The proposed numerical modeling strategy is applied on an industrial blade to analyze the impact of thermal effects on the blade's dynamics.
\end{abstract}

Keywords

rotor/stator interaction; rubbing; nonlinear dynamics; unilateral contact dynamics; friction; abradable coating

1 - Department of Mechanical Engineering, École Polytechnique de Montréal, P.O. Box 6079, Succ. Centre-Ville, Montréal, Québec, Canada H3C 3 A7

\section{Modélisation thermo-mécanique de l'usure du revêtement abradable dans un moteur d'avion}

\author{
F. Nyssen ${ }^{1}$, A. Batailly ${ }^{1}$
}

\begin{abstract}
Résumé
Les moteurs d'avion les plus récents sont conçus pour fonctionner avec des jeux réduits entre les aubes en rotation et le carter environnant, ceci dans le but de maximiser les performances aérodynamiques et donc le rendement global du moteur. La diminution de ces jeux augmente cependant la fréquence des contacts aubes/carter qui peuvent engendrer des phénomènes d'interactions vibratoires préjudiciables. Parmi les moyens existant pour limiter la sévérité de ces contacts, plusieurs fabricants optent pour le dépôt d'un revêtement abradable sur la surface intérieure du carter. Le rôle de ce revêtement est d'assurer un fonctionnement sécuritaire du moteur tout en maintenant un rendement élevé. Toutefois, sous certaines conditions, des niveaux d'usure anormalement élevés ont pu été observés expérimentalement. Les développements présentés ont pour objectif de permettre l'analyse des phénomènes thermo-mécaniques au sein du revêtement abradable à la suite de contacts et de comparer les résultats numériques aux observations expérimentales. Un maillage éléments finis thermique est utilisé sur toute la surface interne du carter. La stratégie numérique présentée repose sur un couplage faible entre phénomènes mécanique et thermique ce qui permet de conserver une certaine efficacité numérique. Problèmes thermiques et mécaniques sont résolus en alternance avec des pas de temps distincts compte-tenu des différentes constantes de temps. La stratégie numérique est appliquée sur une aube industrielle afin d'analyser le lien entre phénomènes thermiques et la réponse vibratoire de l'aube.
\end{abstract}

Mots-clés

interaction rotor/stator; frottement aube/carter; dynamique non-linéaire; dynamique du contact; frottement; revêtement abradable

1 - Département de génie mécanique, École Polytechnique de Montréal, P.O. Box 6079, Succ. Centre-Ville, Montréal, Québec, Canada H3C 3A7 


\section{Introduction}

Improving engine performances is a major issue for turbomachine manufacturers. They seek to lower operating costs while respecting environmental constraints which logically leads to an emphasis on reducing fuel consumption [1]. Modern designs have been developed, leading to: (1) an increase of operating temperatures, (2) an increase of casing conicity (i.e., the variation of casing diameter along the engine axis) which enhances compression rates, (3) the use of lighter materials, as well as (4) more aerodynamically efficient designs. To improve aerodynamic performances of the engine, a common solution consists in the reduction of the nominal clearances between the rotating bladed components (rotor) and the surrounding casing (stator). However, the reduction of the clearance between the tip of the blades and the stator increases the risk of occurrence of unilateral contacts between static and rotating components that may lead to hazardous interaction phenomena. A common technical solution to avoid these interactions consists in depositing a sacrificial abradable coating along the casing contact surface [2, 3, 4]. But contact interactions between the blade-tips and the abradable coating may lead to unexpected abradable wear removal phenomena through various mechanisms, such as thermal gradient in the casing, coincidence of vibration modes, or whirl motions following maneuver loads [5]. For that reason, different researches have been carried out on the blade dynamics in the context of unilateral and frictional contacts $[6,7,8]$. In particular, recent works have focused on the numerical simulation of rotor/stator interactions with wear removal mechanism $[3,9,10,5]$, neglecting thermal effects. But high temperature areas due to contact occurrences have been observed experimentally: the significant rise of temperature that has been measured on several experimental set-up [11] indicates that thermal effects may yield structural deformations and possibly be the cause of very complex material transfer phenomena [12]. For all these reasons, recently developed experimental set-up feature heated contact surfaces [13] and numericists are starting to develop multi-physics strategies and tools [14, 15] dedicated to the prediction of rotor/stator interactions.

Contrary to the work presented in [14] and in [15], that respectively focused on the stator and the bladed disk, the aim of the proposed work is to investigate the numerical modeling of thermal effects specifically within the abradable coating. Indeed, as underlined by previous investigations [16], an accurate description of blade-tip/casing clearance is of prime importance in order to predict sophisticated interactions: any dilatation of the abradable coating due to thermal effects could thus yield significant modifications of the blade dynamics response.

The first section of the article focuses on the theoretical description of the numerical models of the different system components as well as the time integration algorithm. Space and time discretizations for the resolution of the thermal problem are also detailed, with an emphasis on the reduction of computation times. In the second section, the blade heat flux is calibrated using previously published experimental data [17]. The used experimental set-up consists of a full scale bladed disk from an axial high-pressure compressor surrounded with a thick simplified casing on which an abradable coating is thermally sprayed. An infrared camera placed behind the set-up is used to record the temperature evolution during the test. A 22-lobe interaction with 22 hot areas is observed. In the third section, convergence analyses are carried out to study the sensitivity to spatial discretization and time step for the thermal model. In the last section, numerical analyses are performed for different angular speeds. The evolution of the wear and temperature profiles are analyzed in detail.

\section{Modeling}

The proposed work deals with a single rotating blade and the casing on which an abradable layer is deposited to prevent significant damage following contact events. Figure 1 summarizes the different components involved in the modeling. Because of the large size of the finite element model of the blade, a reduced order model (ROM) is computed, embedding centrifugal effects. Only a reduced number of boundary nodes are kept in the ROM at the contact interface along the blade tip. The abradable layer is modeled using one-dimensional two-node rod elements, which are mechanically independent of their adjacent neighbors. The model of material removing for the abradable layer consists in a piece-wise linear plastic constitutive law [5]. In addition to the mechanical mesh used to determine wear evolution, a thermal finite element mesh is added here to compute the temperature evolution in the abradable layer. When contact interactions occur, a heat flux is transmitted from the blade to the abradable coating, increasing the temperature of the impacted abradable coating elements. Then, the heat is conducted inside the abradable layer. The temperature variations induce dilatation of the abradable coating elements. Finally, the 


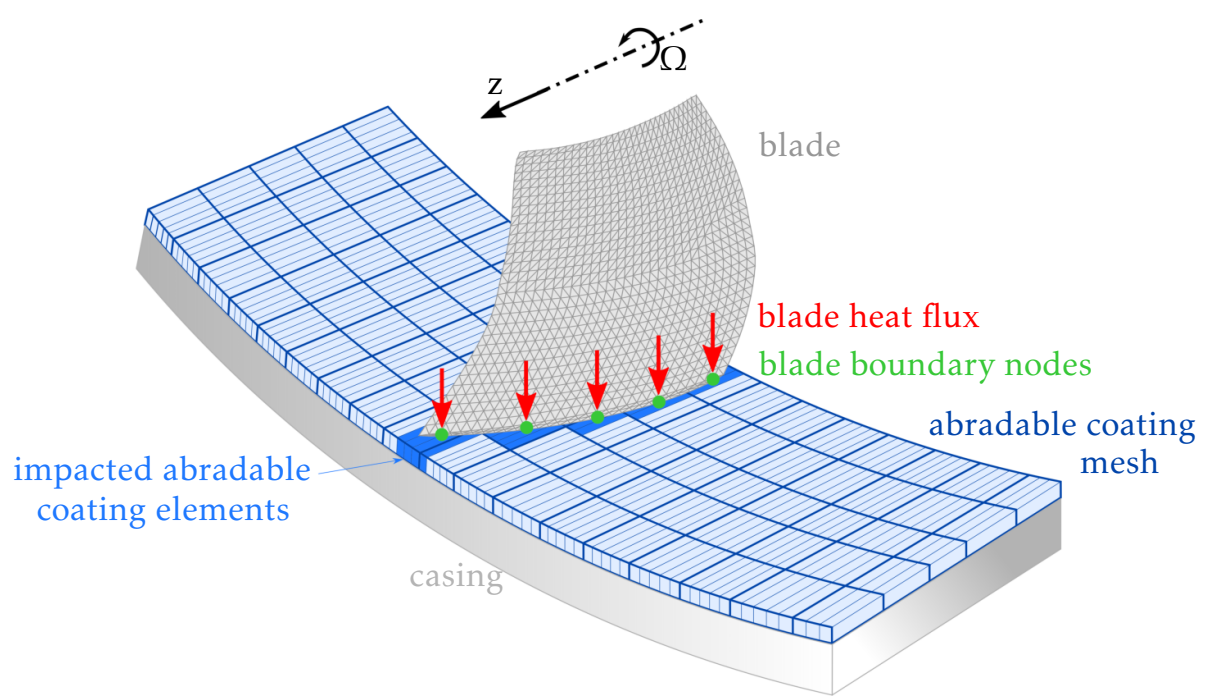

Figure 1. Illustration of the modeled components (blade, abradable coating and casing)

surrounding casing is modeled as a rigid component that remains insensitive to the contact interaction with the blades. A detailed description of each numerical model is given in this section.

\subsection{Blade}

The equation of motion of the blade reads:

$$
\mathbf{M} \ddot{\mathbf{q}}+\mathbf{D} \dot{\mathbf{q}}+\mathbf{K}(\Omega) \mathbf{q}+\mathbf{F}^{c}(\mathbf{q})=\mathbf{F}^{e}
$$

in which $\mathbf{M}, \mathbf{D}$ and $\mathbf{K}$ are respectively the mass, damping and stiffness matrices of the blade finite element model, $\mathbf{q}$ stores the displacements of the blade's degrees of freedom, $\Omega$ is the angular speed, $\mathbf{F}^{c}$ contains the contact forces and $\mathbf{F}^{e}$ refers to the external forces. The contact force vector $\mathbf{F}^{c}$ is computed using Lagrange multipliers [18, 19]. The centrifugal loading acting on the blade affects the computation of the stiffness matrix. As a first approximation, since the angular speed $\Omega$ is constant, the stiffness matrix can be written as a polynomial expansion over the angular speed such as [20]:

$$
\mathbf{K}(\Omega)=\mathbf{K}_{a}+\Omega^{2} \mathbf{K}_{b}+\Omega^{4} \mathbf{K}_{c}
$$

in which the terms $\mathbf{K}_{a}, \mathbf{K}_{b}$ and $\mathbf{K}_{c}$ are expressed using the stiffness matrix computed at three angular speeds $\left(\Omega=0, \Omega_{\max } / 2\right.$ and $\left.\Omega_{\max }\right)$ :

$$
\begin{aligned}
& \mathbf{K}_{a}=\mathbf{K}(0) \\
& \mathbf{K}_{b}=\frac{1}{3 \Omega_{\max }^{2}}\left(16 \mathbf{K}\left(\frac{\Omega_{\text {max }}}{2}\right)-\mathbf{K}\left(\Omega_{\text {max }}\right)-15 \mathbf{K}(0)\right) \\
& \mathbf{K}_{c}=\frac{4}{3 \Omega_{\max }^{4}}\left(\mathbf{K}\left(\frac{\Omega_{\text {max }}}{2}\right)-4 \mathbf{K}\left(\Omega_{\max }\right)+3 \mathbf{K}(0)\right)
\end{aligned}
$$

To reduce the size of the model, a reduction using the transformation matrix $\mathbf{\Phi}$ is applied:

$$
\mathbf{\Phi}=\left[\begin{array}{cc}
\mathbf{I} & \mathbf{0} \\
\mathbf{\Phi}_{R}(0) & \boldsymbol{\Psi}
\end{array}\right]
$$


with:

$$
\boldsymbol{\Psi}=\left[\begin{array}{c}
\boldsymbol{\Phi}_{R}\left(\frac{\Omega_{\max }}{2}\right)-\boldsymbol{\Phi}_{R}(0) \\
\boldsymbol{\Phi}_{R}\left(\Omega_{\max }\right)-\boldsymbol{\Phi}_{R}(0) \\
\boldsymbol{\Phi}_{L}(0) \\
\boldsymbol{\Phi}_{L}\left(\frac{\Omega_{\max }}{2}\right) \\
\boldsymbol{\Phi}_{L}\left(\Omega_{\max }\right)
\end{array}\right]^{\top}
$$

in which $\boldsymbol{\Phi}_{R}(\Omega)$ and $\boldsymbol{\Phi}_{L}(\Omega)$ stand respectively for the $n_{c}$ constraint modes and the first $\eta$ fixed interface modes computed for an angular speed $\Omega$. An orthonormalization of matrix $\boldsymbol{\Psi}$ is performed to avoid potential rank-deficiency due to similarities between the constraint modes. The maximum size of the reduced order model is therefore equal to $3 n_{c}+3 \eta$.

\subsection{Abradable coating}

At each time step, a weak thermo-mechanical coupling is assumed for the abradable coating modeling, meaning that thermal effects affect the system mechanics, but the mechanical deformation of the element has no effect on temperatures. Since mechanics has no effect on thermics, the conduction problem can be first solved separately. Weak coupling is well appropriated in the case of rapid dynamics using small time step and explicit resolution schemes [21]. Moreover, only heat transfer by conduction is considered in this work, convection and radiation effects can be neglected because of their lower contribution to heat transfer in the studied case [4]. The detailed description of the mechanical and thermal model is given in this section.

The mechanical behavior of the abradable coating is modeled using one-dimensional two-node rod elements. Each element is mechanically independent from its adjacent neighbours. Over the thickness of the abradable layer, a single element is used and thermal calculations are performed in a quasi-static framework. It is assumed that the abradable coating elements undergo both elastic $\varepsilon_{e}$ and plastic $\varepsilon_{p}$ deformations following the contact with the blade such as $\varepsilon=\varepsilon_{e}+\varepsilon_{p}$. A plastic constitutive law [5] enables the computation of the normal forces exerted by the blade onto the abradable coating elements and the evolution of the abradable coating profile through permanent plastic deformation.

In addition to the mechanical mesh used to determine the time evolution of the displacement field, a thermal finite element mesh is associated in this work to the abradable coating. Each node of the thermal mesh has one degree of freedom: the temperature of the element. The temperature field in the abradable coating $\mathbf{T}(x, y, z, t)$ reads:

$$
\mathbf{T}(x, y, z, t)=\mathbf{N}(x, y, z) \mathbf{T}(t)
$$

in which $\mathbf{N}(x, y, z)$ is the interpolation function matrix and $\mathbf{T}(t)$ contains the nodal temperatures. The heat equation is given by:

$$
\mathbf{C}_{T} \dot{\mathbf{T}}+\mathbf{K}_{T} \mathbf{T}=\mathbf{F}_{T}
$$

in which the thermal capacity matrix $\mathbf{C}_{T}\left(\right.$ in $\mathrm{J} \cdot \mathrm{K}^{-1}$ ) reads

$$
\mathbf{C}_{T}=\int_{V} \rho c_{P} \mathbf{N}^{T} \mathbf{N} d V
$$

with $\rho$ the abradable density (in $\mathrm{kg} \cdot \mathrm{m}^{-3}$ ) and $c_{P}$ the thermal capacity (in $\mathrm{J} \cdot \mathrm{kg}^{-1} \cdot \mathrm{K}^{-1}$ ). The thermal conductibility matrix $\mathbf{K}_{T}$ (in $\mathrm{W} \cdot \mathrm{K}^{-1}$ ) is given by

$$
\mathbf{K}_{T}=\int_{V} \mathbf{B}^{T} \lambda \mathbf{B} d V
$$

with $\mathbf{B}$ containing the space derivatives of the shape functions, and $\boldsymbol{\lambda}$ the conductivity matrix, which reads, for an isotropic material ( $\lambda$ is the thermal conductivity coefficient of the abradable coating, in $\mathrm{W} \cdot \mathrm{m}^{-1} \cdot \mathrm{K}^{-1}$ )

$$
\boldsymbol{\lambda}=\left[\begin{array}{lll}
\lambda & 0 & 0 \\
0 & \lambda & 0 \\
0 & 0 & \lambda
\end{array}\right]
$$




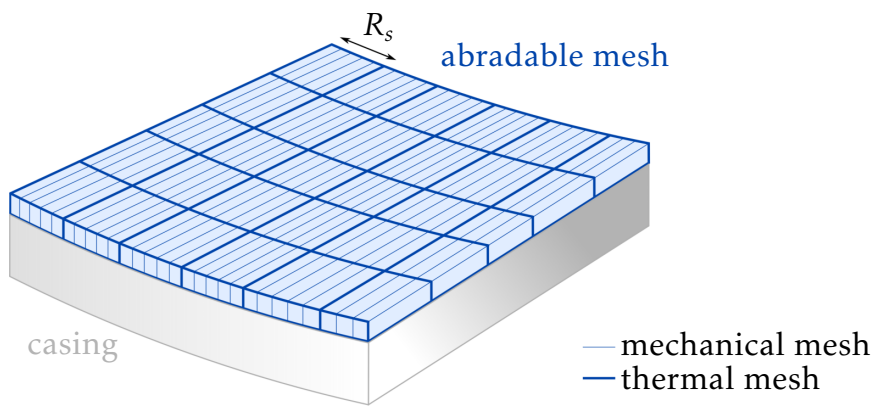

Figure 2. Spatial discretization of the abradable coating mesh

The nodal heat flux vector $\mathbf{F}_{T}$ (in $\mathrm{W}$ ) is given by:

$$
\mathbf{F}_{T}=\mathbf{Q}+\int_{V} \mathbf{N}^{T} \mathbf{q} d V
$$

with $\mathbf{Q}$ the punctual nodal heat sources (in $W$ ) and $\mathbf{q}$ the volumic heat sources (in $\mathrm{W} \cdot \mathrm{m}^{-3}$ ). By convention, the heat flux received by the solid is counted as positive. In this work, there is no volumic heat sources $\mathbf{q}$, and the nodal heat flux $\mathbf{Q}$ is assumed proportional to the amount of removed abradable coating, with a proportionality factor denoted by $q_{T}$. The temperature is assumed to be unknown in all abradable coating elements, except at the initial time where the temperature corresponds to the ambient temperature.

To reduce computational times, a coarser spatial discretization is used for the thermal mesh comparing to the mechanical one. As illustrated in Fig. 2, there is one thermal element for $R_{s}$ mechanical elements in the tangential direction. Therefore, an impact on any of the $R_{s}$ mechanical elements will provide a heat flux for the considered thermal element.

\subsection{Time integration scheme}

To compute the displacement of the blade and the abradable layer wear, an explicit time integration procedure is used in the paper, based on the central finite-differences method. At each iteration $n$, displacements $\mathbf{x}_{n+1}$ are linearly predicted using the following scheme:

$$
\mathbf{x}_{n+1}^{p}=\mathbf{A} \mathbf{x}_{n}+\mathbf{B} \mathbf{x}_{n-1}
$$

with

$$
\begin{aligned}
& \mathbf{A}=\left[\frac{\mathbf{M}}{h^{2}}+\frac{\mathbf{D}}{2 h}\right]^{-1}\left[\frac{2 \mathbf{M}}{h^{2}}-\mathbf{K}\right] \\
& \mathbf{B}=\left[\frac{\mathbf{M}}{h^{2}}+\frac{\mathbf{D}}{2 h}\right]^{-1}\left[\frac{\mathbf{D}}{2 h}-\frac{\mathbf{M}}{h^{2}}\right]
\end{aligned}
$$

in which $h$ is the mechanical time step. If a penetration of the blade within the abradable coating is detected at the time step $n$, predicted displacements are corrected such as:

$$
\mathbf{x}_{n+1}=\mathbf{x}_{n+1}^{p}+\mathbf{C} \boldsymbol{\Lambda}
$$

where $\boldsymbol{\Lambda}$ denotes the contact forces and $\mathbf{C}=\left[\frac{\mathrm{M}}{h^{2}}+\frac{\mathbf{D}}{2 h}\right]^{-1}$.

Since the time constant of thermal effect is larger than contact interactions, a different time discretization is used to compute the evolution of abradable layer temperature. Instead of computing the temperature evolution at each time step, the thermal equation is solved every $R_{t}$ mechanical time steps. The heat flux applied at each thermal time step is equal to the sum of the flux applied on the considered element along the $R_{t}$ last mechanical 


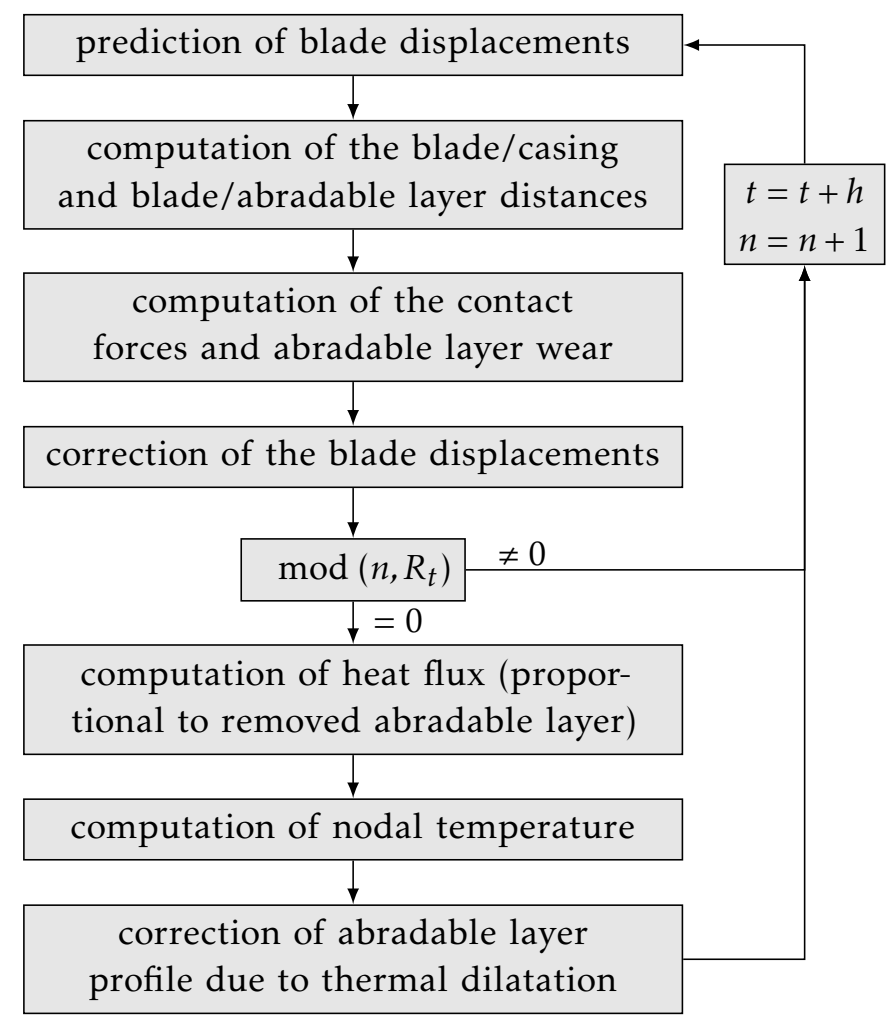

Figure 3. Flow chart of the time integration algorithm

time steps. This enables significant reduction of computational times. The temperature at a given time $t+1$ can be determined using the following equation system [22]:

$$
\begin{aligned}
& \mathbf{T}(t+1)=\mathbf{T}(t)+\overline{\mathbf{K}}_{T}^{-1}(t) \overline{\mathbf{F}}_{T} \\
& \overline{\mathbf{K}}_{T}=\mathbf{C}_{T}+\alpha^{\prime} \Delta t \mathbf{K}_{T} \\
& \overline{\mathbf{F}}_{T}(t)=\Delta t\left(\mathbf{F}_{T}(t)-\mathbf{K}_{T} \mathbf{T}(t)\right)
\end{aligned}
$$

and the initial condition $\mathbf{T}(t=0)=\mathbf{T}_{0} . \alpha^{\prime}$ denotes the parameter of the integration scheme and $\Delta t$ is the thermal time step. $\mathbf{F}_{T}$ contains the heat sources, in this case the heat transmitted by the blade to the abradable coating during contact phase. Denoting $\omega_{\max }$ the largest eigenfrequency of $\mathbf{C}_{T}^{-1} \mathbf{K}_{T}$, one can demonstrate [22] that, in a linear framework, the integration scheme is stable for $\Delta t<\frac{2}{\left(1-2 \alpha^{\prime}\right) \omega_{\max }}$, unconditionally stable for $\alpha^{\prime} \geq \frac{1}{2}$, and stable without oscillation for $\Delta t<\frac{2}{\left(1-\alpha^{\prime}\right) \omega_{\max }}$.

Knowing the temperature evolution in the abradable coating, the displacement field can be updated by computing the element dilatation. Assuming a linear thermo-elastic constitutive law leads to:

$$
\varepsilon_{T}=\alpha_{T} \Delta T
$$

in which $\varepsilon_{T}$ is the thermal deformation, $\alpha_{T}$ is the thermal expansion coefficient and $\Delta T$ is the temperature variation. The dilatation of the abradable layer's mechanical elements due to the increase of temperature computed every $R_{t}$ time step is applied every thermal time step since the increase of temperature are small. The different steps of the time integration algorithm are summarized in Fig. 3. 


\section{Calibration with experimental data}

Recent researches revealed the importance of taking into account thermal effects in the simulation of rotor/stator interactions $[17,14,23]$. The difficulty here is the high difficulty of getting reliable data concerning the temperature achieved in the abradable layer. These measurements are complex since temperature sensors cannot be placed on the abradable coating in operation. The cost of these tests is also prohibitive. The order of magnitude of the temperature within the abradable coating is thus currently inaccurately identified. On one hand, reference [17] refers to an experimental set-up on which the temperature increase was higher than $80^{\circ} \mathrm{C}$ but could not be obtained accurately. On the other hand reference [23] suggests temperature increases as high as $1100^{\circ} \mathrm{C}$. Therefore, due to the current lack of precise experimental data, the proposed calibration remains qualitative only.

The amplitude of the thermal flux is calibrated here using previously published results from an experimental test bench part of the European research program NEWAC [17, 24]. The experimental set-up consists of a full scale bladed disk from an axial high-pressure compressor surrounded with a thick simplified casing on which an abradable coating is thermally sprayed. The angular speed of the bladed disk is driven by an electric motor via a flexible shaft and sealed bearings. The rotor is cantilevered at the end of the shaft. Tests are conducted at room temperature, and in order to limit aerodynamic effects, the set-up is housed in a vacuum chamber [17]. An infrared camera placed behind the set-up is used to record the temperature evolution during the test (Fig. 4). White areas correspond to high temperatures due to repeated contacts between the blade and the abradable coating. A 22-lobe interaction is observed at the tested angular speed. However, the temperature levels achieved during the test were out of the range of the temperature sensors, and the maximum obtained temperature is thus unknown. The aim here is to obtain an order of magnitude of the thermal flux parameter $q_{T}$ to reproduce the results behaviour.

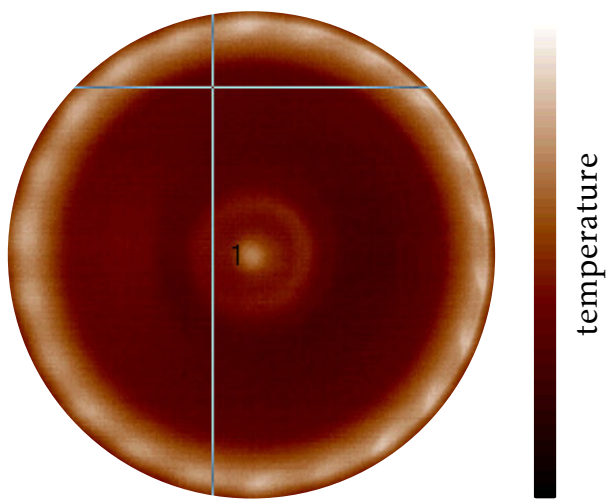

Figure 4. Experimental temperature profile captured with an infrared camera

Test conditions are reproduced numerically to calibrate the heat flux parameter $q_{T}$. Numerical simulations are performed with the finite element mesh of the low pressure compressor blade shown in Fig. 5. Eight nodes along the blade tip are considered at the contact interface in the reduced order model (red dots in Fig. 5). The angular speed of the blade is assumed constant over the simulation. The contact between the blade and the surrounding casing is initiated by quasi-statically applying a two-lobe deformation of the casing in order to absorb the initial clearances. Five blade modes are retained in the reduced order model. The number of mechanical abradable layer elements is fixed to 20 000, which ensure that the convergence has been reached. 100 blade revolutions are simulated.

Figure 6 shows the radial displacement of the blade at the leading edge, mid-cord and trailing edge computed numerically. As in the experiments, the interaction is not diverging since after increasing until around $0.5 \mathrm{~s}$, the amplitude decreases. Details about the comparison between obtained numerical results and experimental observations are detailed in [17] and are not recalled here for the sake of brevity.

Figure 7 gives the wear profile at the end of the simulation at the leading edge, mid-cord and trailing edge. A 22-lobe profile is observed at the leading and trailing edges while 2 lobes are observed at the mid-cord. This shows that the blade vibrates along its first torsion (1T) mode. The higher vibration amplitudes observed at the leading edge explain its higher wear level. The temperature profile can also be observed in Fig. 7 (red line along the 


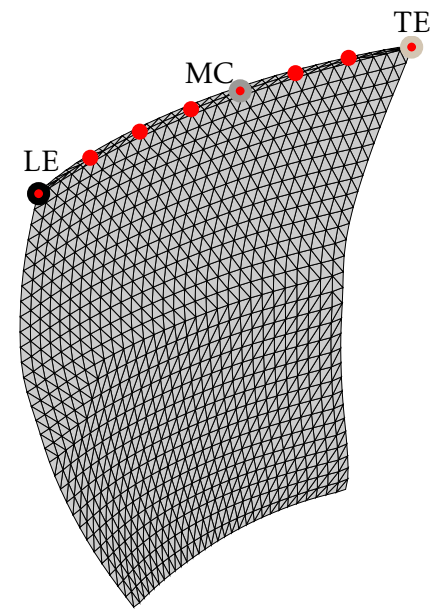

Figure 5. Finite element model of the blade of interest with retained contact nodes at the leading edge (LE), mid-cord (MC) and trailing edge (TE)

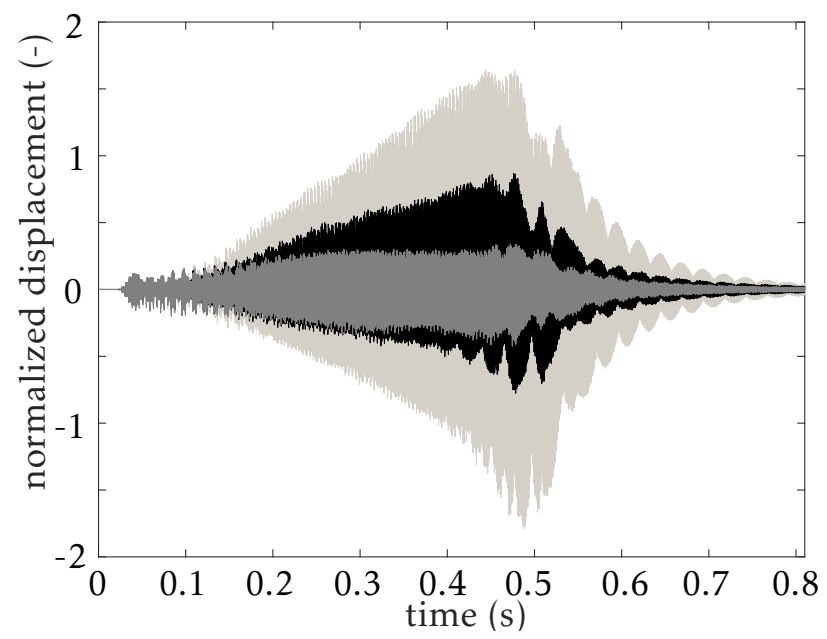

Figure 6. Time evolution of the radial blade displacement at the leading edge $((-))$ ), mid-cord $((-))$, and trailing edges $((-))$

wear profile). Detailed analyses of the time evolution of the temperature in the abradable coating are given in the following sections, but Fig. 7 shows 22 hot spots at the leading edge corresponding to the wear profile, and higher temperature levels are also achieved near the angular positions $\frac{\pi}{2}$ and $\frac{3 \pi}{2}$ because of heat conduction between the mid-cord (with 2 wear lobes) to the leading and trailing edges.

\section{Convergence analysis}

Figures 8 and 9 give the convergence with $R_{s}$ and $R_{t}$ of the wear profile and the time evolution of the maximum temperature after 10 revolutions of the blade. All results are normalized. In both cases, the discretization has almost no impact on the wear profile for the tested values of $R_{s}$ and $R_{t}$. However, there are more notable differences in the time evolution of the maximum temperature. A zoom on the first temperature peak (Fig. 8 and 9 on the right) shows that results are more sensitive to the time discretization than to the spatial discretization. Spatial convergence is achieved for 100 thermal abradable layer elements i.e., $R_{s} \leq 200$, while time convergence shows 
superimposed results.

Figures 10 and 11 show the evolution of the corresponding computation times. Red areas correspond to $R_{s}$ values for which results are not converged. A linear evolution of the computation time with the number of thermal abradable coating elements is observed. A fast reduction of the computation time is also observed for low values of $R_{t}$. The compromise between the convergence and the computation time chosen for the following is 100 thermal abradable coating elements (i.e., $R_{s}=200$ ) and $R_{t}=10$. The chosen configurations are marked with a filled black circle in Fig. 10 and 11.

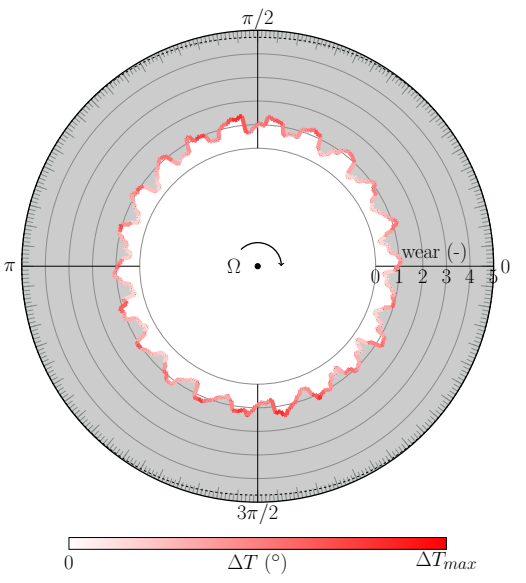

(a) leading edge

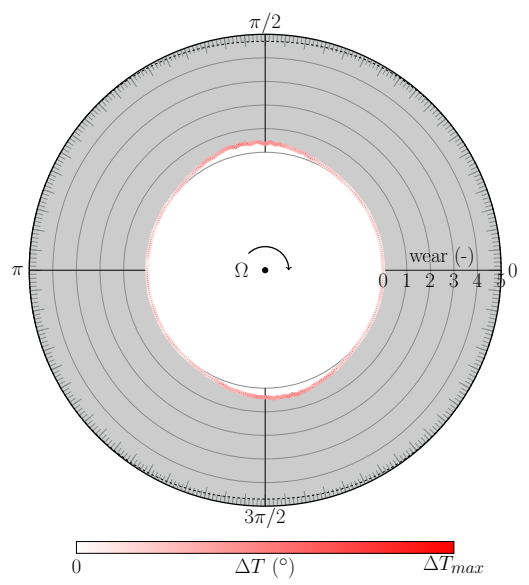

(b) mid-cord

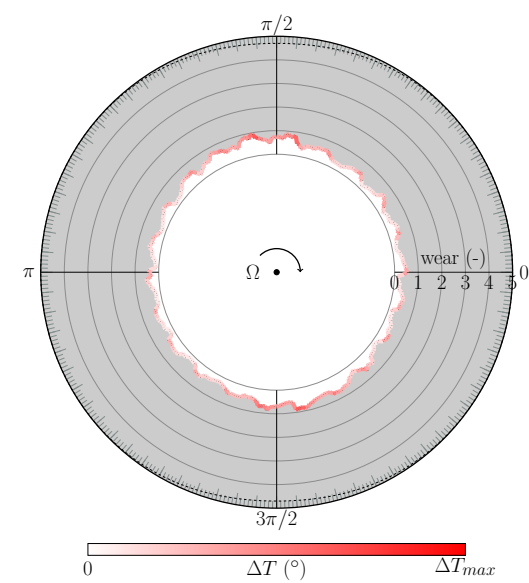

(c) trailing edge

Figure 7. Wear and temperature profiles at $0.51 \mathrm{~s}$

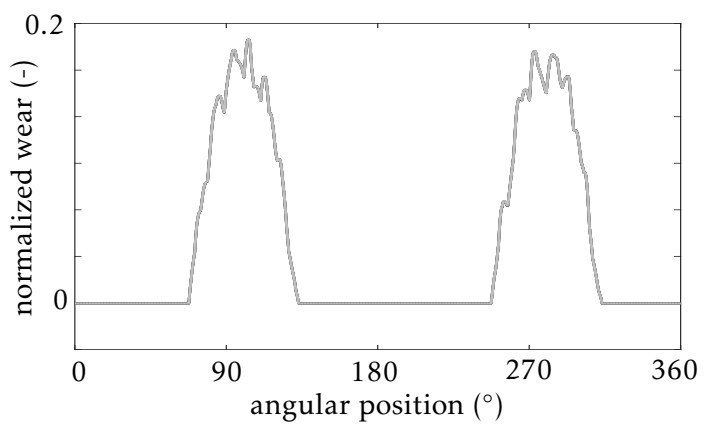

(a) wear
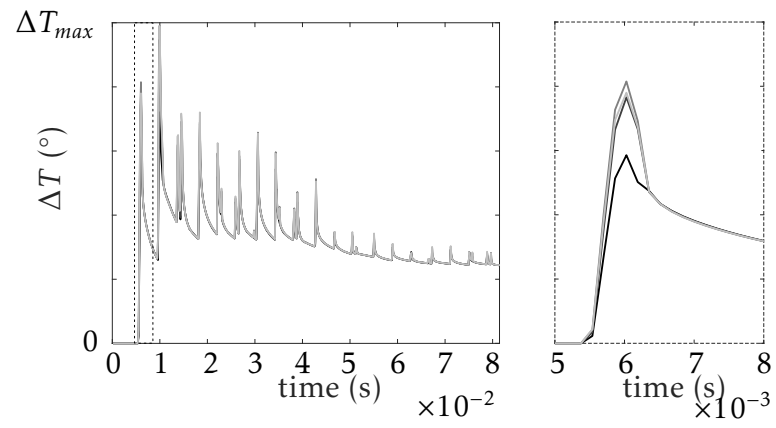

(b) maximum temperature

Figure 8. Convergence analysis of the wear and temperature profiles with the number of thermal abradable coating elements $n_{a b, t h} \cdot n_{a b, t h}=50$ or $R_{s}=400((-)), n_{a b, t h}=100$ or $R_{s}=200((-)), n_{a b, t h}=50$ or $R_{s}=400((-)), n_{a b, t h}=800$ or $R_{s}=25((-))$

\section{Wear and temperature evolution}

In this section, simulations are performed over a wide range of angular speeds. Each simulation is performed at constant angular speed on 100 blade revolutions. The contact between the blade and the surrounding casing is initiated here by applying a uniform deformation along the circumference, which can correspond to a uniform abradable dilatation following an increase of the airflow temperature. The blade heat flux parameter $q_{T}$ used here is 


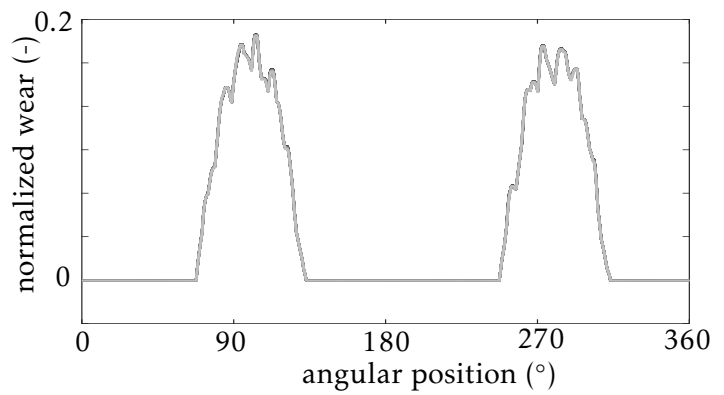

(a) wear
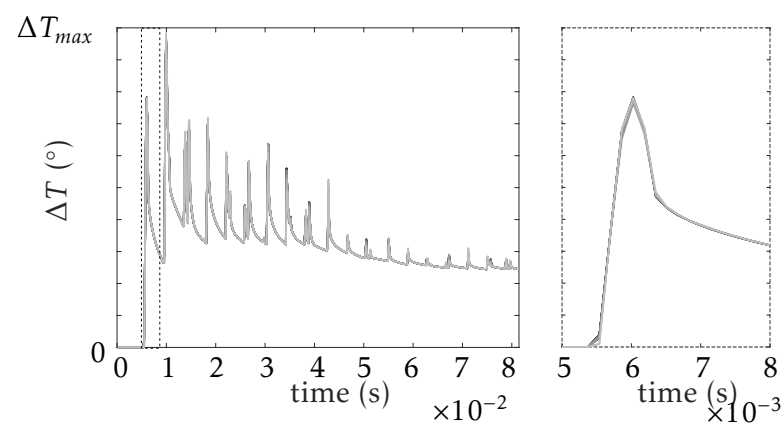

(b) maximum temperature

Figure 9. Convergence analysis of the wear and temperature profiles $R_{t} \cdot R_{t}=1((-)), R_{t}=5((-)), R_{t}=10((-))$, $R_{t}=15((-)), R_{t}=20((-)), R_{t}=25((-)), R_{t}=50((-)), R_{t}=100((-)), R_{t}=150((-)), R_{t}=200$ $((-)), R_{t}=300((-))$

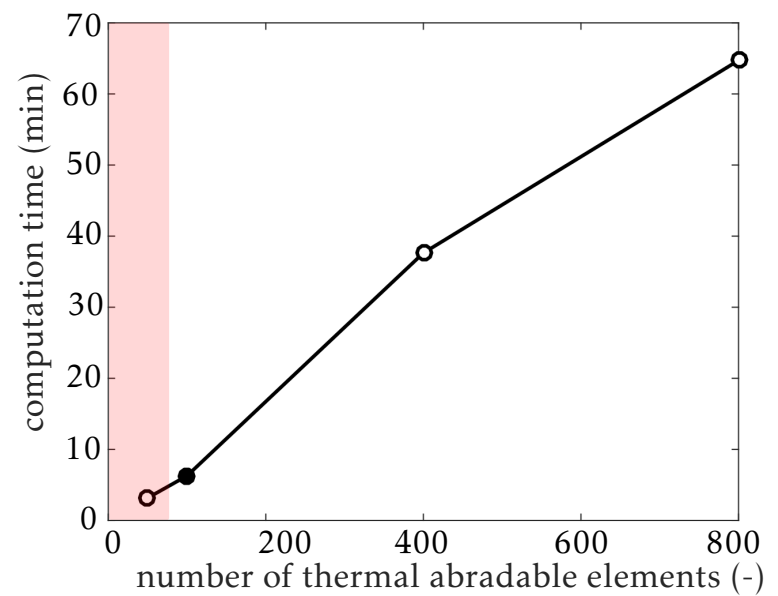

Figure 10. Evolution of the computation time with the number of thermal abradable coating elements

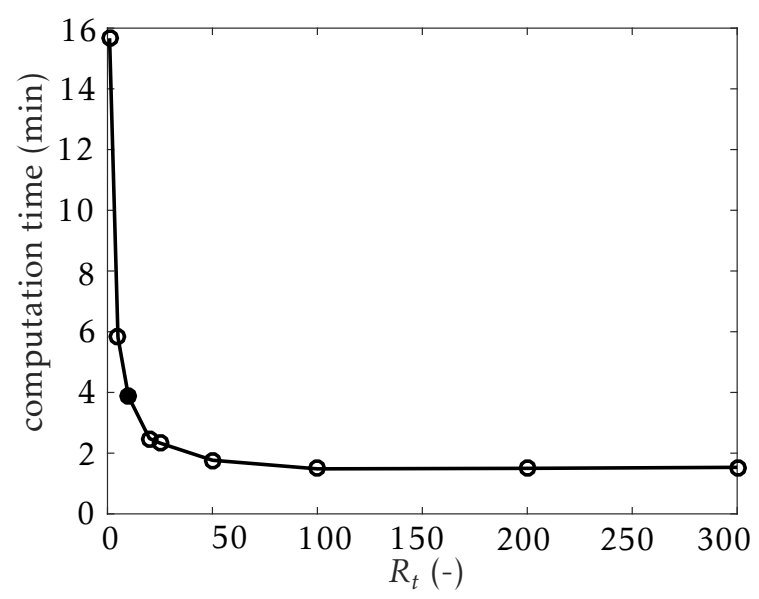

Figure 11. Evolution of the computation time with $R_{t}$ 
the one calibrated based on experimental data. The finite element model and the material parameters are the same as in previous sections. All results are normalized.

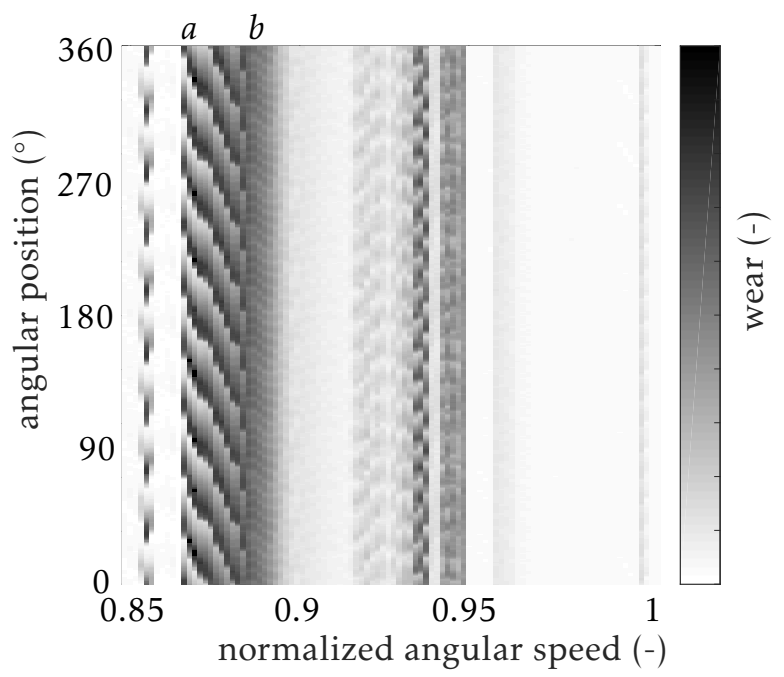

Figure 12. Wear map at the trailing edge

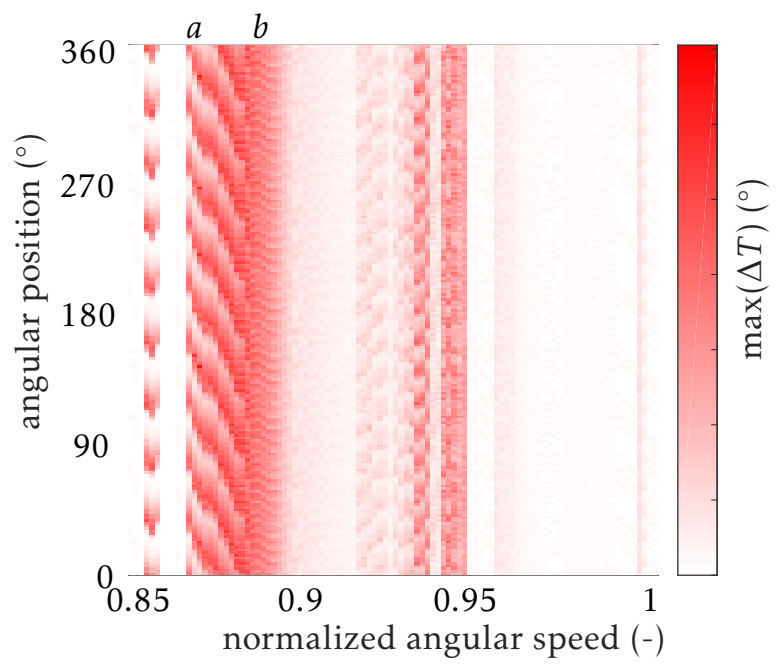

Figure 13. Temperature map at the trailing edge

Figure 12 shows the evolution of the wear profile for different angular speeds at the trailing edge along the circumference of the abradable coating taking into account thermal effects. Several interaction areas can be clearly identified. A 9-lobe wear profile is observed at the beginning of the range of angular speeds of interest with a high level of wear, while 17-lobes are observed in the middle of the range of angular speeds of interest. Figure 13 gives the corresponding evolution of the maximum temperature for different angular speeds at the trailing edge along the circumference of the abradable coating. Since the blade heat flux is defined as proportional to the amount of abradable layer wear, areas of high level of wear achieve higher maximum temperature. The temperature map exhibits the same number of lobes as the wear map of Fig. 12.

Two angular speeds, marked as $a$ and $b$ in Fig. 12 and 13, are analyzed with more details. The maximum achieved temperatures have the same order of magnitude for these two angular speeds. Figures 14a and 14b show the 


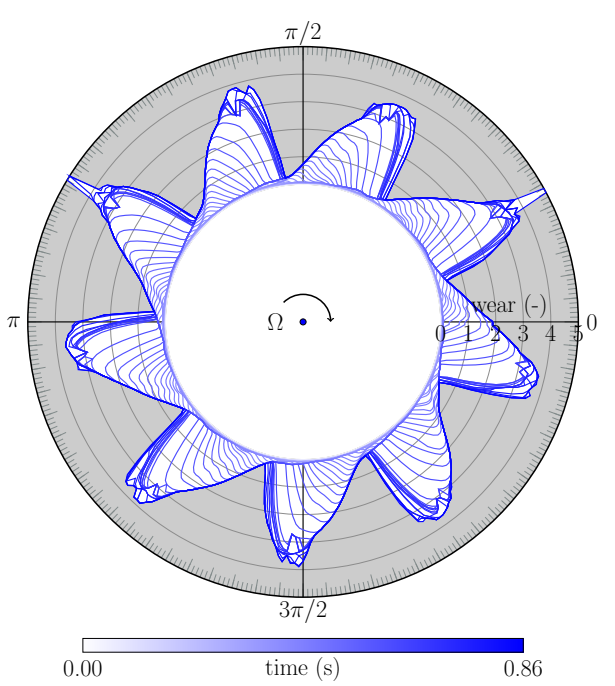

(a) angular speed $a$

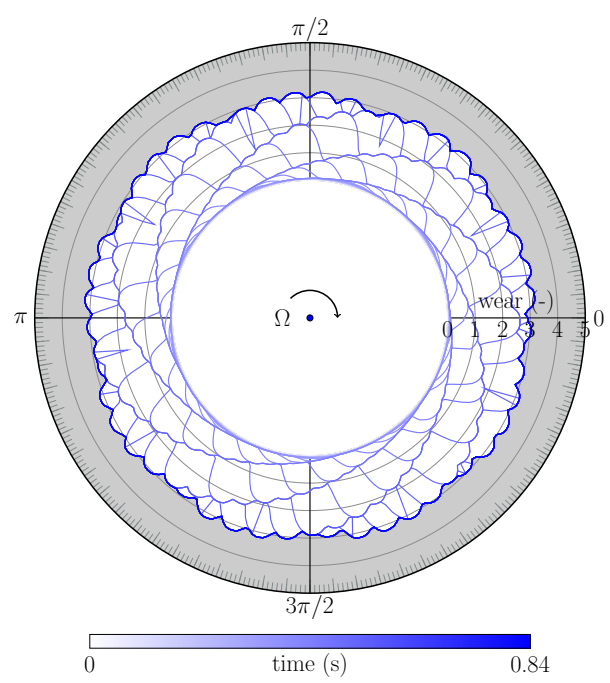

(b) angular speed $b$

Figure 14. Time evolution of the wear profile at the trailing edge

time evolution of the wear in polar coordinates. Light blue curves correspond to the wear profile at the beginning of the simulation, while darker lines correspond to the last revolutions. For angular speed $a$, the abradable is removed during a large number of blade revolutions and yield a 9-wear lobe profile, while for angular speed $b$, the abradable is removed in only a few blade revolutions with a lot of contact points (44-lobe wear as evidenced in Fig. 14b). Since the blade heat flux is defined as proportional to the amount of wear, the heat flux per blade revolution is lower for angular speed $a$ because of the more progressive wear. The temperature increases is also progressive (black curve in Fig. 15, the maximum temperature occurs at $t=t_{a}$ ). For angular speed $b$, the temperature increase rapidly at the angular positions of the wear lobes because of the high amount of abradable removed and the high number of contact areas. The time evolution of the maximum temperature is shown in Fig. 15 (grey curve, the first temperature peak occurs at $t=t_{b}<t_{a}$ ). Figures 16a and 16b give the temperature profile along the circumference of the abradable coating for angular speeds $a$ and $b$ at $t_{a}$ and $t_{b}$ respectively. High temperatures are localized in front of the 9 wear lobes for angular speed $a$. A more uniform temperature along the abradable coating circumference is observed for angular speed $b$ because of the higher number of contact areas (44 lobes).

However, the case at angular speed $a$ would intuitively lead to higher temperatures near the contact areas than the one at angular speed $b$ because of the repetitive friction of the blade on the abradable coating. A more accurate prediction of the blade heat flux could be to compute it as proportional to the friction between the blade and the abradable layer. This point will be investigate in future works.

\section{Conclusion}

This paper investigates the numerical modeling of thermal effects in the abradable coating. A mechanical mesh made of independent two-node rod elements with elasto-plastic constitutive law is considered to compute the abradable layer wear. A thermal mesh of the abradable layer has been added to compute the evolution of the temperature in the abradable coating due to blade contacts. A calibration of the blade heat flux when the abradable coating is removed has been carried out using pre-existing experimental data. To reduce computation times of the temperature simulation, a different space and time discretization has been used to solve the thermal and mechanical equations. A convergence analysis has been performed, which shows that the space and time discretization has negligible effect once convergence has been reached on the obtained wear profile. However, higher differences are observed on the time evolution of the temperature, particularly on the peaks values following the contact between the blade and the abradable coating. A compromise between the computation times and the results accuracy has been found. 


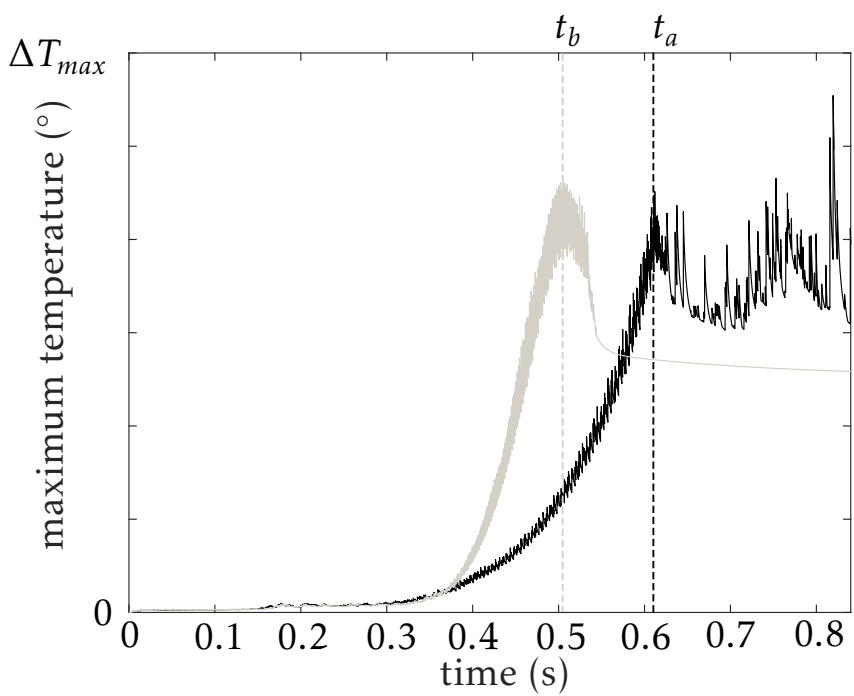

Figure 15. Time evolution of the maximum temperature for the angular speeds $a\left(\left(-\square^{-}\right)\right.$and $b((-))$

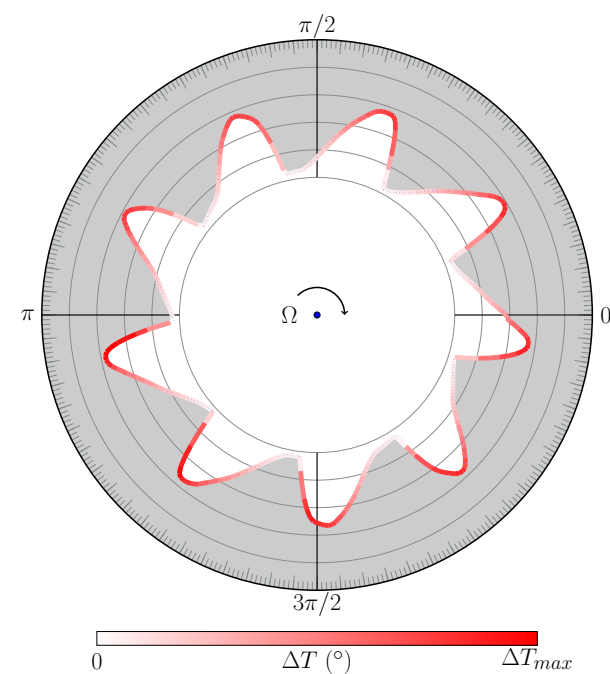

(a) angular speed $a$

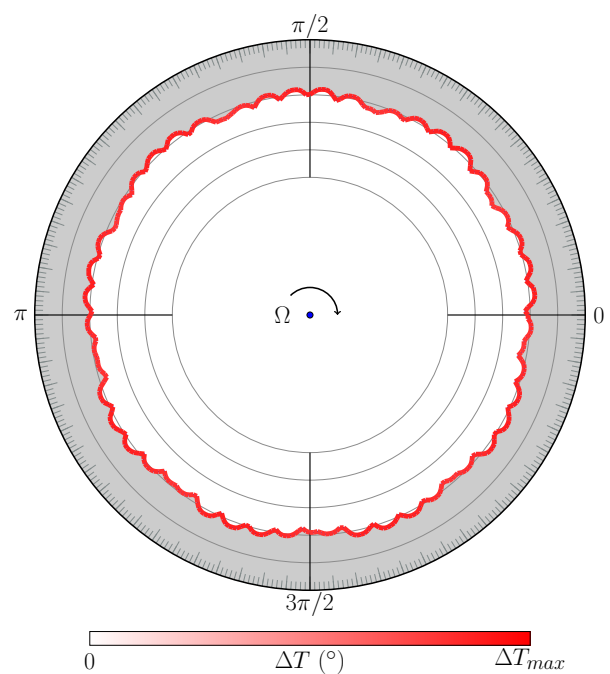

(b) angular speed $b$

Figure 16. Temperature and wear profile at the trailing edge

In future works, the numerical model may be improved by considering temperature diffusion inside of the casing, providing casing dilatation. The two-dimensional model (tangential-axial) has to be extended to three dimensions (tangential-axial-radial). Moreover, a more intuitive prediction of the blade heat flux could be to compute it as proportional to the friction between the blade and the abradable. Finally, a dependence of the mechanical property of the abradable coating with temperature should be included. Nevertheless, this work provides bases for the modeling of thermal effects within the abradable coating on which further refinements can be integrated.

Modeling the thermal effects offers new insights over only modeling mechanical effects. Thermo-mechanical modeling is necessary since high temperature areas due to contact occurrences have indeed been observed experimentally, that may yield structural deformations and may explain the observed material transfer phenomena. 


\section{Acknowledgment}

This research was supported by the Natural Sciences and Engineering Research Council of Canada (NSERC). The authors are also grateful to the industrial partner for supporting this project, Safran Aircraft Engines.

\section{References}

[1] Williams, R. J., 2011. "Simulation of blade casing interaction phenomena in gas turbines resulting from heavy tip rubs using an implicit time marching method". In Proceedings of the ASME Turbo Expo 2011 conference, GT2011-45495. doi: 10.1115/GT2011-45495 - oai: hal-01555287.

[2] Muszynska, A., Bently, D., Franklin, W., Hayashida, R., Kingsley, L., and Curry, A., 1989. Influence of rubbing on rotor dynamics - part 1. Tech. Rep. NAS8-36179, NASA. oai: 19890016092.

[3] Borel, M., Nicoll, A., Schlapfer, H., and Schmid, R., 1989. "The wear mechanisms occurring in abradable seals of gas turbines". Surface \& Coatings Technology, 39, pp. 117-126. doi: 10.1016/0257-8972(89)90046-7 - oai: hal-00627526.

[4] Mandard, R., Witz, J.-F., Boidin, X., Fabis, J., Desplanques, Y., and Meriaux, J., 2015. "Interacting force estimation during blade/seal rubs". Tribology International, 82, pp. 504-513. doi: 10.1016/j.triboint.2014.01.026 - oai: hal-01093168.

[5] Legrand, M., Batailly, A., and Pierre, C., 2011. "Numerical investigation of abradable coating removal through plastic constitutive law in aircraft engine". Journal of Computational and Nonlinear Dynamics, $\mathbf{7}$, pp. 011010-1-11. doi: 10.1115/1.4004951 - oai: hal-01555287.

[6] Sinha, S. K., 2005. "Non-linear dynamic response of a rotating radial timoshenko beam with periodic pulse loading at the free end". International Journal of Non-Linear Mechanics, 40, pp. 113-149. doi: 10.1016/j.ijnonlinmec.2004.05.019.

[7] Lesaffre, N., Sinou, J. J., and Thouverez, F., 2007. "Stability analysis of rotating beams rubbing on an elastic circular structure". Journal of Sound and Vibration, 299(4-5), pp. 1005-1032. doi: 10.1016/j.jsv.2006.08.027 oai: arXiv:0801.3775.

[8] Legrand, M., Pierre, C., Cartraud, P., and Lombard, J. P., 2009. "Two-dimensional modeling of an aircraft engine structural bladed disk-casing modal interaction". Journal of Sound and Vibration, 319(1-2), pp. 366-391. doi: 10.1016/j.jsv.2008.06.019 - oai: hal-00328186v2.

[9] Salles, L., Blanc, L., Thouverez, F., and Gouskov, A., 2010. "Dynamic analysis of fretting wear in friction contact interfaces". International Journal of Solids and Structures, 48(10), pp. 1513-1524. doi: 10.1016/j.ijsolstr.2011.01.035.

[10] Baï, S., 2011. "Etude expérimentale du contact aube/abradable : contribution à la caractérisation mécanique des matériaux abradables et de leur interaction dynamique sur banc rotatif avec une aube". PhD thesis, Ecole Centrale de Lille. oai: tel-00605091.

[11] Millecamps, A., Brunel, J., Dufrénoy, P., Garcin, F., and Nucci, M., 2009. "Influence of thermal effects during blade-casing contact experiments". In Proceedings of the ASME 2009 IDETC \& CIE conference, ASME. doi: 10.1115/DETC2009-86842 - oai: hal-01223060.

[12] Delebarre, C., Wagner, V., Paris, J.-Y., Dessein, G., Denape, J., and Santanach, J. G., 2017. "Tribological characterization of a labyrinth-abradable interaction in a turbo engine application". Wear, 370-371, pp. 29-38. doi: 10.1016/j.wear.2016.11.007 - oai: hal-01758599.

[13] Mandard, R., Desplanques, Y., Hauss, G., Fabis, J., Witz, J.-F., and Meriaux, J., 2015. "Mechanisms of incursion accommodation during interaction between a vibrating blade and an abradable coating". Wear, 330(Supplement C), pp. 406 - 418. doi: 10.1016/j.wear.2015.01.014 - oai: hal-01203253.

[14] Agrapart, Q., Dufrénoy, P., Desplanques, Y., Brunel, J.-F., and Millecamps, A., 2017. "Modélisation thermomécanique du contact aube-abradable dans les turboréacteurs". In Proceedings of the Congrès Français de Mécanique. pdf: 133795 - oai: hal-01768624. 
[15] Guérin, N., Thouverez, F., Gibert, C., Legrand, M., and Almeida, P., 2017. "Thermomechanical component mode synthesis for blade casing interaction prediction". In Proceedings of the ASME Turbo Expo 2017 conference, GT2017-64342. doi: 10.1115/GT2017-64342 - oai: hal-01569918.

[16] Batailly, A., Legrand, M., Millecamps, A., and Garcin, F., 2015. "Conjectural bifurcation analysis of the contactinduced vibratory response of an aircraft engine blade". Journal of Sound and Vibration, 348(Supplement C), pp. 239 - 262. doi: 10.1016/j.jsv.2015.03.005 - oai: hal-01223575.

[17] Batailly, A., Agrapart, Q., Millecamps, A., and Brunel, J.-F., 2016. "Experimental and numerical simulation of a rotor/stator interaction event within an industrial high-pressure compressor". Journal of Sound and Vibration, 375, pp. 308 - 331. doi: 10.1016/j.jsv.2016.03.016 - oai: hal-01342401.

[18] Laursen, T., 2002. Computational contact and impact mechanics. Springer.

[19] Wriggers, P., 2002. Computational contact mechanics. John Wiley \& Sons.

[20] Sternchüss, A., and Balmès, E., 2006. "On the reduction of quasi-cyclic disks with variable rotation speeds". Proceedings of the International Conference on Advanced Acoustics and Vibration Engineering (ISMA), pp. 39253939.

[21] Adam, L., 2003. "Modélisation du comportement thermo-élasto-viscoplastique des métaux soumis à grandes déformations. application au formage superplastique.". Ph.D. thesis, Université de Liège, Liège, Belgium.

[22] Debard, Y., 2011. Méthode des éléments finis : thermique. Université du Mans.

[23] Xue, W., Gao, S., Duan, D., Zheng, H., and Li, S., 2017. "Investigation and simulation of the shear lip phenomenon observed in a high-speed abradable seal for use in aero-engines". Wear, 386-387, pp. 195-203. doi: 10.1016/j.wear.2017.06.019.

[24] http://www.newac.eu. 